\title{
Seasonal Cycle of Volume Transport through Kerama Gap Revealed by a 20-year Global HYbrid Coordinate Ocean Model Reanalysis \\ By
}

Zhitao Yu ${ }^{\mathrm{a}, \mathrm{b}^{*}}$, E. Joseph Metzger ${ }^{\mathrm{b}}$, Prasad Thoppil ${ }^{\mathrm{b}}$, Harley E. Hurlburt ${ }^{\mathrm{c}}$, Luis Zamudio ${ }^{\mathrm{c}}$, Ole Martin Smedstad ${ }^{\mathrm{d}}$, Hanna Na ${ }^{\mathrm{e}}$, Hirohiko Nakamura ${ }^{\mathrm{f}}$, and Jae-Hun Park ${ }^{\mathrm{g}}$

${ }^{\mathrm{a}}$ American Society of Engineering Education, DC, USA

${ }^{\mathrm{b}}$ Naval Research Laboratory, Stennis Space Center, MS, USA

${ }^{\mathrm{c}}$ Florida State University, Tallahassee, FL, USA

${ }^{\mathrm{d}}$ Vencore, Incorporated, Stennis Space Center, MS, USA

${ }^{\mathrm{e}}$ Faculty of Science, Hokkaido University, Sapporo, Japan

${ }^{\mathrm{f}}$ Faculty of Fisheries, Kagoshima University, Kagoshima, Japan

${ }^{\mathrm{g}}$ Korea Institute of Ocean Science and Technology, Ansan, South Korea

*Correspondence to:

Zhitao Yu

Oceanography Division

Naval Research Laboratory

Stennis Space Center, MS 39529

Email: zhitao.yu.ctr@nrlssc.navy.mil 


\section{Abstract}

The temporal variability of volume transport from the North Pacific Ocean to the

3 East China Sea (ECS) through Kerama Gap (between Okinawa Island and Miyakojima

4 Island - a part of Ryukyu Islands Arc) is investigated using a 20-year global HYbrid

5 Coordinate Ocean Model (HYCOM) reanalysis with the Navy Coupled Ocean Data

6 Assimilation from 1993 to 2012. The HYCOM mean transport is $2.1 \mathrm{~Sv}$ (positive into the

7 ECS, $1 \mathrm{~Sv}=10^{6} \mathrm{~m}^{3} / \mathrm{s}$ ) from June 2009 to June 2011, in good agreement with the

8 observed 2.0 Sv transport during the same period. This is similar to the 20-year mean

9 Kerama Gap transport of $1.95 \pm 4.0 \mathrm{~Sv}$. The 20 -year monthly mean volume transport

10 (transport seasonal cycle) is maximum in October (3.0 Sv) and minimum in November

11 (0.5 Sv). The annual variation component (345-400 days), mesoscale eddy component

12 (70 - 345 days), and Kuroshio meander component ( $<70$ days) are separated to determine

13 their contributions to the transport seasonal cycle. The annual variation component has a

14 close relation with the local wind field and increases (decreases) transport into the ECS

15 through Kerama Gap in summer (winter). Most of the variations in the transport seasonal

16 cycle come from the mesoscale eddy component. The impinging mesoscale eddies

17 increase the transport into the ECS during January, February, May, and October, and

18 decrease it in March, April, November, and December, but have little effect in summer

19 (June - September). The Kuroshio meander components cause smaller transport

20 variations in summer than in winter. 


\section{1. Introduction}

25 The Kuroshio is one of the world's major western boundary currents and a key

26 feature of North Pacific Ocean circulation. It originates from the North Equatorial

27 Current (Gordon et al., 2014) and then enters the East China Sea (ECS) through the East

28 Taiwan Channel (ETC) between Taiwan and Ishigaki Island; it carries warm and saline

29 waters poleward (Oka and Kawabe, 1998), and exits the ECS through Tokara Strait

30 (Figure 1). Estimates of the mean Kuroshio transport in the ECS vary from 18.5 to $32 \mathrm{~Sv}$

31 (Roemmich and McCallister, 1989; Johns et al., 2001; Andres et al., 2008b). Because the

32 Kuroshio transports significant amounts of heat, salt, and mass from the tropical ocean to

33 mid-latitudes, it has a great influence on the global climate and heat balances (Qu and

34 Lukas, 2003), and on the fisheries, hydrography, and weather of countries surrounding

35 the Northwestern Pacific (Qiu, 2001).

36 The Ryukyu Islands Arc forms a barrier along the eastern side of the ECS and

37 separates the ECS from the North Pacific except at connecting straits. Thus, except at the

38 entrance (ETC) and exit (Tokara Strait), the water in the ECS and the North Pacific

39 exchanges through many channels in the Ryukyu Islands Arc. Kerama Gap, located

40 between Miyakojima and Okinawa (Figure 1), is the deepest channel with a sill depth of

$411050 \mathrm{~m}$ (Choi et al., 2002) and thus has been the subject of significant research.

42 Analyzing moored current meter (CM) observations, Yuan et al. (1994) reported an

43 observed 5.8 Sv outflow (from the ECS to the Northwestern Pacific) through the passages

44 between Miyakojima and Okinawa during Fall 1991; but Yuan et al. (1995) estimated a

45 2.4 Sv inflow (from the Northwestern Pacific into the ECS) from November 1991 to

46 September 1992. Morinaga et al. (1998) estimated a 7.2 Sv inflow through Kerama Gap 
47 from their CM observations during two months from July to September 1992. The wide

48 range of observed transports can be attributed to the relatively short observation duration

49 periods covering different observation times and is indicative of the large temporal

50 variations in transport through Kerama Gap. The annual mean transport through Kerama

51 Gap remained uncertain until Na et al. (2014) reported a 2.0 Sv mean flow into the ECS

52 based on two years of observations covering June 2009 to June 2011. The standard

53 deviation is $3.2 \mathrm{~Sv}$, which is much larger than the 2-year mean inflow and comparable to

54 the standard deviation of the downstream PN-line (Figure 1, black line) Kuroshio

55 transport (4.0 Sv) (Andres et al., 2008b). Hence, Kerama Gap transport may have a

56 significant impact on the temporal variability of the Kuroshio transport in the ECS.

57 Classical theories have shown that mid-latitude eastward flows have a

58 spontaneous tendency to develop wavelike disturbances due to baroclinic instability

59 (Kundu and Cohen, 2002). Since the Kuroshio Extension and the Subtropical

60 Countercurrent both exist at mid-latitudes, there is no surprise that mesoscale eddies are

61 ubiquitous outside of the ECS with the Ryukyu Islands Arc acting as a barrier. Andres et

62 al. (2008a, b) show that the eddies arriving from the ocean interior affect the transport

63 through Kerama Gap and then the Kuroshio transport in the ECS. Andres and Cenedese

64 (2013) further found laboratory support for Andres et al. (2008a, b). Jin et al. (2010), on

65 the other hand, argued that a shifting of the Kuroshio mean current axis and the

66 approaching eddies are both important in determining flow direction through Kerama

67 Gap. The preceding results indicate the important role of the Kerama Gap in the

68 interaction of the ECS Kuroshio with the ocean interior and on water exchange through

69 the Ryukyu Islands Arc. 
In a numerical attempt to simulate Ryukyu currents with climatological forcing,

71 You and Yoon (2004) reported a 5.6 Sv inflow through the passages between

72 Miyakojima and Okinawa. In their model, spatial resolution is $1 / 6^{\circ}$. Guo et al. (2006) ran

73 a $1 / 18^{\circ}$ nested ocean model using weekly forcing over the period from September 1991 to

74 December 1998 and found an inflow of $0.49 \mathrm{~Sv}$ between Miyakojima and Okinawa.

75 Soeyanto et al. (2014) estimated a 0.18 Sv inflow through Kerama Gap by analyzing the

76 results from a 20-year (1993-2012) reanalysis output by a data-assimilative ocean model,

77 which is based on the Princeton Ocean Model with a generalized coordinate system,

78 developed in Japan Coastal Ocean Predictability Experiments 2. Their model includes

79 two sub-models that are connected by a one-way nesting system and the horizontal grid

80 interval for the inner model $\left(10.5^{\circ}-60^{\circ} \mathrm{N}, 108^{\circ}-180^{\circ} \mathrm{E}\right)$ is $1 / 12^{\circ}$. All of these numerical

81 studies reported inflow through Kerama Gap, which is consistent with Na. et al. (2014),

82 yet the mean transport is quite different. Kerama Gap has very steep topography and its

83 width is only about $50 \mathrm{~km}$. Thus, resolving the transport requires fine horizontal

84 resolution and a vertical coordinate system capable of resolving the vertical structure of

85 flow from the surface to the sill depth. Additionally, data assimilation of sea surface

86 height $(\mathrm{SSH})$ is necessary for the model to capture the temporal transport variation

87 generated by approaching eddies.

88 Na et al. (2014) has investigated the dynamics at Kerama Gap and reported the

89 mean transport. To elucidate the dynamics underlying the variation of transport through

90 Kerama Gap, it is necessary to estimate its variability at various timescales. However, the

91 2-year observational period is not long enough to determine variability in timescales

92 longer than one year. In this study, we present a 20-year (1993-2012) transport time 
93 series through Kerama Gap from a data assimilative global HYbrid Coordinate Ocean

94 Model (HYCOM) reanalysis. The long transport time series provides a unique

95 opportunity that allows us to define the seasonal cycle and to investigate the impact of

96 transport variability at different time scales on the seasonal cycle. Previous studies

97 (Sugimoto et al., 1988; Qiu et al., 1990; James et al., 1999; Ichikawa, 2001; Nakamura et

98 al., 2003) also show that two types of Kuroshio meanders exist in the northern Okinawa

99 trough with periods less than 70 days. Thus, we focus on three bands with periods of 345

$100-400$ days (annual variation), 70 - 345 days (mesoscale eddy), and shorter than 70 days

101 (Kuroshio meander) and also examine their respective contributions to the seasonal cycle.

102 The paper is organized as follows: the numerical model used in this study is described in

103 section 2. Model comparisons with observational data are presented in section 3.

104 Transport variability is described in section 4. Dynamics underlying the transport

105 variability are discussed in section 5, followed by conclusions in section 6 .

\section{2. Numerical Model}

107 HYCOM is a primitive equation general ocean circulation model applied to large

108 scale, marginal sea, and coastal studies. A detailed description of HYCOM physics can

109 be found in Bleck (2002). Below, HYCOM is briefly presented with emphasis on the

110 model aspects that are relevant for this study.

111 HYCOM solves five prognostic equations: two for horizontal velocity

112 components, a mass continuity equation, and two conservative equations that govern

113 temperature and salinity. The prognostic equations are time-integrated using a split-

114 explicit treatment of barotropic and baroclinic modes. There are three vertical-coordinate

115 systems coexisting in HYCOM: z-coordinates in unstratified water, sigma-coordinates in 
116 shallow depths, and isopycnal coordinates in the stratified ocean. Hence, HYCOM

117 maintains the significant advantages of an isopycnal model in the stratified ocean, but

118 allows coordinate surfaces to locally deviate from isopycnals to provide more vertical

119 resolution near the surface and in shallow coastal regions in order to better represent the

120 upper ocean physics (Chassignet et al., 2003). With this unique feature, HYCOM serves

121 as a good tool for simulating circulations near Kerama Gap, which has complex

122 topography that covers the shallow water near Kerama Gap and Okinawa Island, the

123 Okinawa trough, slope, and the deep ocean.

124 The data assimilation scheme employed for the reanalysis is a three dimensional

125 variational scheme (3DVAR) used within the Navy Coupled Ocean Data Assimilation

126 (NCODA) (Cummings, 2005; Cummings and Smedstad, 2013). The ocean data sets

127 assimilated by NCODA include: remotely sensed sea surface temperature (SST), SSH,

128 and sea ice concentration; plus in-situ surface and subsurface observations of temperature

129 and salinity. An important component within NCODA is forming 3D synthetic profiles

130 from the 2D SSH and SST, since there are only very limited subsurface profile data to

131 constrain the system. In the global HYCOM reanalysis, HYCOM assimilates synthetic

132 temperature profiles computed using the Modular Ocean Data Assimilation System

133 (MODAS), which models the time-averaged co-variability of SSH and subsurface

134 temperature at a given location (Fox et al., 2002). Salinity is then estimated from the

135 synthetic temperature profiles using temperature-salinity regression relationships derived

136 from the historical profiles archived in the MODAS database.

137 Global HYCOM is eddy resolving with an equatorial horizontal resolution of

$1380.08^{\circ}\left(1 / 12.5^{\circ}\right)$. There are 32 hybrid vertical coordinate layers with potential density 
139 referenced to $2000 \mathrm{~m}$, the same as the present operational US Navy Global Ocean

140 Forecast System version 3.0 (Metzger et al., 2014). The surface wind and thermal forcing

141 are the $0.3125^{\circ} 1$-hourly Climate Forecast System Reanalysis (CFSR) products provided

142 by National Centers for Environmental Prediction (NCEP) (Saha et al., 2010). The ocean

143 reanalysis was initialized from a non-assimilative global HYCOM simulation spun-up to

144 statistical equilibrium using a climatology of NCEP CFSR forcing. The data assimilation

145 began on October 1, 1992 and the mesoscale eddy field adjusted to the satellite altimeter

146 data within the first month. We analyzed model output over the period January 1993

147 through December 2012.

\section{3. Model Comparisons with Observational Data}

149 In this section, we compare HYCOM reanalysis results with observational results

150 which were obtained by Na et al. (2014) during two years from June 2009 to June 2011 at

151 an array of current and pressure-recording inverted echo sounders (CPIESs) and CM

152 moorings. The cross-section, formed with four CPIESs (ES1 to ES4, red dots in Figure 1)

153 and three CMs (CM1-3, white dots in Figure 1), is located between ES1 and ES4. The

154 HYCOM transect starts from the grid point nearest to ES1 and ends at the grid point

155 closest to ES4, forming a $45^{\circ}$ angle with respect to due east (Figure 1, gray line). To be

156 consistent with observations, a 72-hour low-pass filter was applied to the daily transport

157 time series from the HYCOM reanalysis.

\section{$158 \quad 3.1$ Current Velocity in Kerama Gap}

159 Three CMs mentioned above and deployed during the 2-year observational period

160 are CM1 to CM3 (from southwest to northeast) with $\sim 15 \mathrm{~km}$ spacing between each

161 mooring. The HYCOM grid points closest to the location of the three CMs are chosen to 
162 represent the model location of the CMs. Velocity time series are extracted from the

163 "model CM" locations, linearly interpolated to the CM depth, and then temporally

164 averaged and compared with observations (Figure 2). The average distance between the

165 "model CM" and the deployed CM location is $\sim 3 \mathrm{~km}$, larger than one third of the grid

166 interval. Given the very steep cross-channel bathymetry and a $\sim 50 \mathrm{~km}$ channel width, it

167 can be difficult to obtain a good point-to-point model-data comparison. Below we first

168 compare the yearly averaged currents at each CM in different layers and then provide the

169 correlation coefficient to determine the temporal agreements between the reanalysis and

170 observed current time series. The 2-year observational period is not sufficiently long to

171 discuss the annual variation component. So we only focus on the mesoscale eddy and the

172 Kuroshio meander components for the 2-year observational period.

173 In the upper (Figure 2a, b) and middle (Figure 2c, d) layers of Kerama Gap, both

174 the observations (black) and reanalysis (red) show the strongest mean currents at CM3

175 (the northeasternmost CM). Following Na et al. (2014) analysis, we divide the period into

176 year-1 (June 2009 - June 2010) and year-2 (June 2010 - June 2011). In both year-1 and

177 year-2, the mean currents gradually decrease from northeast (CM3) toward the southwest

178 (CM1) in Kerama Gap. The magnitude of the mean currents is reproduced better than the

179 mean current direction. This discrepancy may be due to the topographic difference

180 between reality and numerical model, as the current direction is more highly sensitive to

181 the local topography compared with the current speed.

182 In the upper layer (Figure 2a, b), the observations in year-1 show that mean 183 currents at CM2 flow more normal to rather than parallel to the mean CM3 current

184 direction. The HYCOM reanalysis correctly reproduces this characteristic. The year-2 
185 reanalysis accurately reproduces the mean current direction in the upper layer for both 186 CM1 and CM3.

187 In the middle layer (Figure 2c, d), mean current directions in both the 188 observations and HYCOM reanalysis are almost parallel to each other at CM2 and CM3

189 while the northwestward mean current direction in observations is not reproduced in the 190 HYCOM reanalysis. At CM1, the HYCOM reanalysis mean current in year-1 shows 191 weak outflow $(2.3 \mathrm{~cm} / \mathrm{s})$ that is different from the observations showing even weaker 192 inflow $(0.7 \mathrm{~cm} / \mathrm{s})$. The HYCOM reanalysis mean current direction (into the ECS) is more 193 consistent with the observations during year-2 than year-1 and the HYCOM reanalysis 194 reproduces observations that the inflow at CM1 in year-2 is larger than in year-1.

195 The biggest discrepancy between the HYCOM reanalysis and current 196 observations is in the deep layer (Figure 2e, f), near the bottom. Though both the 197 reanalysis and observations show mean inflow through Kerama Gap into ECS, the inflow 198 magnitude $(17.3 \mathrm{~cm} / \mathrm{s})$ of the reanalysis is much larger than observed $(2.5 \mathrm{~cm} / \mathrm{s})$ at the 199 center of Kerama Gap (CM2). The HYCOM reanalysis appears to have bottom-trapped 200 inflow at CM2 with the maximum occurring near the sill depth (Figure 3a) while 201 observations (Figure 3c) do not show this feature. The cause of the excessive deep flow 202 appears to be related to the use of MODAS synthetic profiles within NCODA that are 203 used for projecting surface information downward into the water column. Cummings 204 (2005) notes that MODAS has marginal skill in areas where profiles are limited, and the 205 historical database seems inadequate to statistically represent the Ryukyu Current in the 206 vicinity of Kerama Gap. A data-assimilative Pacific basin HYCOM hindcast spanning the $207 \mathrm{Na}$ et al. (2014) observational time period uses an improved methodology, Improved 
208 Synthetic Ocean Profiles (ISOP), for the downward projection of surface information

209 (Helber et al., 2013) and shows better current structure agreement (Figure 3b) with

210 observations than the reanalysis, which supports the above explanation.

211 Nakamura et al. (2013) compared currents in the deep layer (black arrow in

212 Figure 2e and f) with currents observed by ES5 (location shown in Figure 1, green dot) at

213 a depth of $1366 \mathrm{~m}, 50 \mathrm{~m}$ above the sea floor, and suggested a thin vertical layer near the

214 bottom with intensified inflow across Kerama Gap. Results from the data-assimilative

215 Pacific HYCOM hindcast (Figure 3b) agrees with this suggestion, though the currents in

216 the bottom layer are not as strong as observed and the area with intensified bottom flow

217 exists only on the northeastern sill.

218 Thoppil et al. (2015) compared the reanalysis results with 3.5 years of moored

219 CM observations (Ryukyu currents) during December 1998 through October 2002 to the 220 southeast of Amami-Ohshima Island (Ichikawa et al., 2004). Their comparison has shown

221 good agreement at depths of 2000, 3000, and even below $4000 \mathrm{~m}$ (at these depths, the

222 flow is not constrained by the data assimilation). Thus the mismatch of the bottom

223 current through Kerama Gap shouldn't be interpreted against the deep circulation of the

224 reanalysis in general but rather confirms that MODAS has marginal skill in areas where 225 profiles are limited.

226 The time series of the mesoscale eddy and Kuroshio meander components are 227 calculated respectively by applying a band pass filter for periods of 70-345 days and a

228 high pass filter for periods shorter than 70 days to the time series of total velocity 229 component along Kerama Gap. The Fourier filter takes the Fourier transform of the time 230 series, manipulates the specific frequency components, and finally inverse transforms the 
231 results. The correlation coefficients between reanalysis and observed along Kerama Gap

232 velocity are summarized in Table 1 for the two different components. The correlation

233 coefficients are all significant to the $95 \%$ confidence level calculated based on a student $t$

234 distribution and 50-74 equivalent degrees of freedom (EDOF) for the eddy component

235 and 402-654 EDOF for the Kuroshio meander component. It can be seen that the

236 mesoscale eddy components are highly correlated and have a much higher positive

237 correlation coefficient (greater than 0.62 in the upper layer) than the Kuroshio meander

238 components (between 0.22 and 0.29 in the upper layer) in general except in the deep

239 layer (CM2) and the middle layer of CM3. Mesoscale eddies are well integrated into the

240 reanalysis through $\mathrm{SSH}$ data assimilation. The less significant correlation in the deep

241 layer of $\mathrm{CM} 2$ and the middle layer of CM3 reflects that MODAS has marginal skill for

242 projecting surface information downward into the water column in the northeast Kerama 243 Gap.

\section{$244 \quad 3.2$ Volume Transport through Kerama Gap}

245 Volume transport through a zonal (meridional) HYCOM transect is calculated as

246 the product of the meridional (zonal) depth integrated barotropic velocity and the transect

247 length. Volume transport through a diagonal HYCOM transect is estimated as a sum of

248 the transport through the zonal and meridional transects, which starts from either end of

249 the diagonal transect and ends at where the two transects intersect. Na et al. (2014)

250 estimates that $60 \%$ of the mean transport is in the upper $500 \mathrm{~m}$. The global HYCOM

251 reanalysis indicates that $61 \%$ of the mean transport is in the upper $750 \mathrm{~m}$ (Figure 3a),

252 whereas the data-assimilative Pacific HYCOM hindcast indicates $65 \%$ of the mean

253 transport is in the upper 500m (Figure 3b), a better agreement with the observations. This 
254 Pacific hindcast has a Kerama Gap mean transport of $2.05 \mathrm{~Sv}$ that also closely agrees

255 with the observational estimate. Thus the mean inflow into the ECS does not appear to be

256 sensitive to the vertical structure of the currents and the conclusions drawn from the 20-

257 year reanalysis are not impacted by the difference in the flow structure at the deep layer.

258 The HYCOM 20-year-long time series of volume transport through Kerama Gap

259 is shown in Figure 4a (red line). The time series during 2-year observation period is

260 shown in Figure 4b. The HYCOM reanalysis (red line in Figure 4b) agrees well with

261 observations (black line in Figure 4b) but has slightly larger mean and variability. The

262 mean total transport through Kerama Gap in the 2-year hindcast is $2.1 \mathrm{~Sv}$ (Table 2) into

263 the ECS while the observation is $2.0 \mathrm{~Sv}$, which is well within the standard error of

264 estimate from the observations $(0.7 \mathrm{~Sv})$. The estimation error of the 2-year hindcast

265 transport with respect to observed transport is $\pm 0.4 \mathrm{~Sv}$ based on the auto-covariance

266 function (Dewar and Bane, 1985) of the transport difference time series.

267 During the 2-year observational period, the HYCOM reanalysis captures the

268 temporal transport variability well (Figure $4 b$ ). The correlation coefficient between these

269 two time series is 0.71 , and this increases to 0.82 after applying a 20 -day smoother to

270 both time series. The correlation coefficient between the reanalysis and observation time

271 series is 0.88 for the mesoscale eddy component, and 0.41 for the Kuroshio meander 272 component.

273 Statistics for the two time series are shown in Table 2. The HYCOM reanalysis

274 mean transports and standard deviations are all higher than the observed values except

275 the mean transport for the second year. The HYCOM 2-year transport standard deviation

276 is $4.2 \mathrm{~Sv}, 31 \%$ greater than the observed value. The HYCOM reanalysis shows that there 
277 is more flow into the ECS through Kerama Gap and more transport variation in year-2

278 (June 2010 to June 2011) than in year-1 (June 2009 to June 2010), in accord with the

279 observations. The transport difference between year-1 and year-2 will be discussed

280 further in section 5.2.

281 4. Transport Variability

282 The variance preserving power spectra of the 20-year-long transport time series is 283 shown in Figure 5. We divide the transport time series into four period bands: (1) inter284 annual variation component with periods longer than 400 days, (2) annual variation 285 component with periods between 345 and 400 days, (3) mesoscale eddy component with 286 periods between 70 and 345 days, and (4) Kuroshio meander component with periods 287 shorter than 70 days. Most of the variation comes from the mesoscale eddy and Kuroshio 288 meander components, which explain $41.3 \%$ and $43.9 \%$ of the total variance, respectively.

289 The inter-annual component accounts for $12.5 \%$ of the total variance, while the annual 290 variation component contains only $2.3 \%$ of the total variance. In this section, we focus on 291 the seasonal cycle of volume transport through Kerama Gap (Figure 6), and examine how

292 it is affected by each of the components mentioned above (Figure 7, red, green, and blue 293 lines) except the inter-annual variation component (Figure 7, black dashed line).

294 4.1 Mean Transport and Seasonal Cycle

295 The HYCOM 20-year mean transport through Kerama Gap is $1.95 \mathrm{~Sv}$ into the 296 ECS, with a standard deviation of $4.0 \mathrm{~Sv}$. The uncertainty estimation of the 20 -year mean 297 transport is $\pm 0.28 \mathrm{~Sv}$. Thus the $1.95 \mathrm{~Sv}$ mean is statistically significant.

298 By averaging the total transport month-by-month over the 20-year period, we 299 obtain the 20-year mean seasonal cycle of transport through Kerama Gap (Figure 6a, 
300 black solid line) and the associated uncertainty (Figure 6a, shaded area). The most

301 statistically significant feature of the seasonal cycle is that the maximum transport occurs

302 in October (3.04 Sv) followed by the minimum transport in November $(0.54 \mathrm{~Sv})$.

\section{$303 \quad 4.2$ Annual Variation Component}

304 We obtain the annual variation component (Figure 7, red) by applying a band pass

305 Fourier filter for periods of 345-400 days to the total transport time series. Explaining 306 only $2.3 \%$ of the total variance, the amplitude of the annual variation component is as 307 large as $2.0 \mathrm{~Sv}$ in 1997 and as small as $0.3 \mathrm{~Sv}$ in 2002 . The standard deviation is $0.77 \mathrm{~Sv}$.

308 The 20-year monthly mean of the annual variation component indicates a clear cycle 309 through Kerama Gap: inflow (0.34 Sv) into the ECS in summer and outflow (-0.34 Sv)

310 from the ECS in winter (Figure 6b, red line). The total transport inflow (Figure 6a, black

311 line) in summer is dominated by the annual variation component (Figure 6b, red line).

3124.3 Mesoscale Eddy Component

313 Previous studies (Feng et al., 2000; Zhang et al., 2001; Hsin et al., 2008; Lee et

314 al., 2013) have attributed the long-term intra-annual (periods longer than 70 days)

315 Kuroshio transport variability to interior Pacific mesoscale eddies. Similarly, Na et al.

316 (2014) reported that the impinging mesoscale eddies from the interior Pacific Ocean are

317 responsible for the long-term intra-annual variability through Kerama Gap. Thus we

318 apply a band pass Fourier filter for periods of 70-345 days to the total transport time

319 series and name the filtered time series the mesoscale eddy component (Figure 7, green).

320 This component has a standard deviation of $2.90 \mathrm{~Sv}$.

321 The 20-year monthly mean of the mesoscale eddy component (Figure 6b, green

322 line) follows the seasonal cycle closely (Figure 6a, black solid line). Its contribution to 
323 the seasonal cycle can be divided into three different stages: (1) neutral stage with a small

324 magnitude from June through September, (2) an inflow stage in January, February, May,

325 and October, and (3) an outflow stage in March, April, November, and December. The

326 maximum occurs in October with $1.0 \mathrm{~Sv}$ of inflow and the minimum occurs in November

327 with $0.9 \mathrm{~Sv}$ of outflow.

\section{4.4 Kuroshio Meander Component}

329 The short-term intra-annual (periods shorter than 70 days) Kuroshio fluctuations

330 have been attributed to two types of Kuroshio meanders: (1) variations of the Kuroshio

331 path meander with periods between 30 and 70 days (Ichikawa, 2001; Zhang et al., 2001;

332 Nakamura et al., 2003), and (2) variations of the Kuroshio subsurface temperature frontal

333 meander with periods shorter than 30 days (Sugimoto et al., 1988; Qiu et al., 1990; James

334 et al., 1999; Feng et al., 2000). In this study, we apply a high pass Fourier filter for

335 periods shorter than 70 days to the total transport time series to obtain the Kuroshio

336 meander component (Figure 7, blue line). The standard deviation of this component is

$3372.97 \mathrm{~Sv}$, larger than both annual variation and mesoscale eddy components. The transport

338 variation related with this component (Figure 6b, blue line) has a smaller magnitude from

339 May to September compared to the rest.

340 5. Discussion

3415.1 Transport through Kerama Gap in relation to transport through Miyakojima to

342 Okinawa and the PN line

343 Kerama Gap has been suggested as a key region for interaction between the ECS-

344 Kuroshio and the Ryukyu Current (Nitani 1972; Andres et al. 2008a, b; Jin et al. 2010),

345 but the deep gap's width $(\sim 50 \mathrm{~km})$ is much less than the total distance from Miyakojima 
346 to Okinawa $(250 \mathrm{~km})$. The HYCOM 20 -year reanalysis provides an opportunity to

347 compare the mean transport through the smaller passage (Kerama Gap) and the larger

348 passage (from Miyakojima to Okinawa). Mean transport through the passage between

349 Miyakojima and Okinawa is $2.03 \mathrm{~Sv}$ into ECS, with a standard deviation of $5.74 \mathrm{~Sv}$. The

350 mean transport through Kerama Gap represents $96 \%$ of the mean transport between

351 Miyakojima and Okinawa. Thus the transport through Kerama Gap is confirmed to be a

352 good approximation to the mean transport between Miyakojima and Okinawa, as

353 mentioned earlier in section 1.

354 To confirm the conclusions derived from observations that Kerama Gap transport 355 may have a significant impact on the temporal variability of the Kuroshio transport in the

356 ECS, we calculate the standard deviation of the transport through Kerama Gap and the

357 PN line every year. The two time series of standard deviation are highly correlated with a

358 correlation coefficient of 0.64 (Figure 8), confirming that the temporal variability of the

359 Kuroshio transport in the ECS (PN line) corresponds well with the transport variation

360 through Kerama Gap.

\subsection{Transport in Year-1 vs. Year-2}

362 In this subsection, we explain a possible mechanism underlying the $1.0 \mathrm{~Sv}$ inflow

363 increase from year-1 (1.6 Sv) to year-2 $(2.6 \mathrm{~Sv})$ in the HYCOM reanalysis. The yearly

364 averaged inter-annual variation component (black dashed line in Figure 7 in which the

$3651.95 \mathrm{~Sv}$ mean transport is removed) is $0.3 \mathrm{~Sv}$ in year-2 and $-0.3 \mathrm{~Sv}$ in year-1, and thus

366 explains the transport increase of $0.6 \mathrm{~Sv}$ from year-1 to year-2. The 2-year average inter-

367 annual signal is zero, which helps to explain why the 2-year mean transport is almost the

368 same as the 20-year mean. Cummings and Smedstad (2013) have already verified that the 
369 assimilated SSH field in the Kuroshio region shows good agreement with independent

370 infrared frontal analyses performed by the Naval Oceanographic Office. Thus we treat

371 the assimilated SSH as the "true" state. The yearly averaged SSH difference, defined as

372 SSH in year-2 minus in year-1, shows an anomalous cyclone to the south-southeast of

373 Kerama Gap (Figure 9) with an SSH difference across the HYCOM Kerama Gap transect

374 of $1.1 \mathrm{~cm}$. The correlation coefficient between the SSH difference across the HYCOM

375 Kerama Gap transect and the transport through Kerama Gap is 0.83 over the 20-year

376 reanalysis period. The regression coefficient between the SSH difference across the

377 HYCOM Kerama Gap transect and transport is $0.46 \mathrm{~Sv} / \mathrm{cm}$. Thus the SSH difference

378 between year-2 and year-1 explains $0.5 \mathrm{~Sv}$ of the transport difference. This indicates that

379 the difference between yearly averaged transport in year- 1 and year- 2 corresponds well

380 with the difference between yearly averaged SSH differences in year-1 and year-2. It can

381 be concluded that about one half of the increase of yearly averaged inflow from year-1 to

382 year-2 can be attributed to the increase of yearly averaged inter-annual variation

383 component of inflow transport which is accompanied with the development of an

384 anomalous cyclonic eddy to the south-southeast of Kerama Gap from year-1 to year-2.

\section{$385 \quad 5.3$ Ekman Dynamics}

386 The dynamics underlying the annual variation component are attributed to the 387 wind-driven Ekman transport. The mean winds over the broad shelf of the ECS are 388 dominated by the East Asia monsoon. In summer (June-August), the wind is north389 northwestward at Kerama Gap (Figure 10a), while in the winter (December to February)

390 the wind is southwestward and stronger (Figure 10b). With the prevailing seasonal wind

391 blowing toward the northwest (southwest) persistently in summer (winter), water piles up 
392 on the northeast (northwest) flank of Kerama Gap due to Ekman transport. Thus the

393 corresponding geostrophic flow is northwestward (southwestward), parallel to the wind

394 direction and causes the water to flow into (out of) the ECS through Kerama Gap. The

395 annual variation component of area-averaged (between $126.0^{\circ}$ and $127.5^{\circ} \mathrm{E}, 25.4^{\circ}$ and

$\left.39626.7^{\circ} \mathrm{N}\right)$ monthly along Kerama Gap wind stress anomaly $\left(30^{\circ}\right.$ counter-clockwise from

397 north) shows good agreement with the monthly transport of the annual variation

398 component (Figure 10c) and the correlation coefficient is 0.55. Hsin et al. (2010) found a

399 similar relationship near southeastern Taiwan, where the geostrophic velocity and local

400 meridional wind stress are generally well-correlated on the seasonal time scale.

\section{$401 \quad 5.4$ Monthly Mean SSH Anomaly}

402 Unlike Na et al. (2014), the mesoscale eddy component is represented by a group

403 of peaks with similar amplitude (Figure 5) in the period band 70-200 days, instead of a

404 single dominant peak at $~ 100$-day period. The period band 70-200 days agrees well with

405 the dominant time scale of the transport mode through the ETC reported by Zhang et al.

406 (2001). Spectral analysis using the reanalysis transport time series from only the 2-year

407 observational period does show a single dominant peak at $~ 100$-day period, the same as

408 observations. This indicates that time intervals of arriving mesoscale eddies from the

409 interior ocean vary with time over the 20 -year period, and are not dominated by a single

410 100-day time period.

411 In order to explain the monthly mean of the mesoscale eddy component (green

412 line in Figure 6b), we generated a monthly mean SSH anomaly (SSHA) map centered on

413 Kerama Gap (Figure 11). An EOF analysis was performed and the leading mode of the

414 annual steric effect (Stammer, 1997) was also removed. Depending on the eddy location, 
415 the same type of eddy can increase or decrease transport through Kerama Gap. The

416 mesoscale eddies typically propagate into this region as part of the return flow of the

417 Kuroshio's non-linear recirculation gyre. Therefore, it can be concluded that the

418 Kuroshio's non-linear recirculation gyre is one of the possible reasons for the significant

419 month to month variations shown in Figure 11. Andres et al. (2008a) show that positive

420 transport anomalies in Kerama Gap are associated with the arrival of anticyclonic eddies

421 along the eastern side of Okinawa, while negative transport anomalies are associated with

422 the arrival of cyclonic eddies. Na et al. (2014) find that cyclonic (anticyclonic) eddies

423 increase (decrease) transport through Kerama Gap when these eddies are located to the

424 south of Kerama Gap.

425 Below, we examine the reason why the contributions of eddies to the transport 426 seasonal cycle are large in January to May and October to December (Figure 6b, green 427 line), and small from June to September. During the inflow stage, an anomalous

428 anticyclone is located to the east of Okinawa in January and to the southeast of Kerama

429 Gap in February. A dipole with an anticyclone (cyclone) attached to the northern

430 (southern) Kerama Gap is shown in October. When both eddies pump water into ECS

431 through Kerama Gap, the maximum inflow occurs in October. But the SSHA map in May

432 shows an exception. When a cyclone is located to the east of Okinawa in May, the eddy

433 should decrease transport (Andres et al., 2008a) instead of increasing transport (Figure $4346 b$, green line).

435 A cyclonic eddy located to the east of Okinawa and an anti-cyclonic eddy to the 436 south/southeast of Kerama Gap is consistent with outflow from the ECS through Kerama 437 Gap, as occurs in March and April. But during November and December, an elongated 
438 anticyclonic eddy that straddles the entire passage from Miyakojima to Okinawa

439 separates two cyclones located to the southeast and northwest of Kerama Gap. The

440 anticyclone straddling Kerama Gap would suggest weak flow instead of the strong

441 outflow shown by the monthly mean.

442 The vertical structure of the normal velocity anomaly in May (November and

443 December) shows that subsurface water primarily flows into (out of) the ECS through

444 Kerama Gap. Jin et al. (2010) applied the self-organizing map to study the interaction

445 between the ECS and the Ryukyu Current through Kerama Gap. Four coherent patterns

446 were extracted to illustrate how eddies in the ECS interact with eddies in the Ryukyu

447 Current to alter the flow through Kerama Gap. The velocity anomaly structure in May

448 (Figure 12a) and November (Figure 12b) belongs to patterns P4 and P3 (Figures 2d and c

449 in Jin et al., 2010, respectively). Thus the transport anomaly in May, November, and

450 December (velocity anomaly structure in December is very similar to November and is

451 not shown) is caused by eddy interactions on the western and eastern sides of Kerama

452 Gap and is associated with deeper levels, but is not represented by the SSHA.

453 Small eddy contributions to the transport seasonal cycle from June to September

454 indicate that the impact of eddies on the transport through Kerama Gap is small during

455 these four months and the SSHA maps confirm this. The cyclonic eddies are either far 456 away from Kerama Gap (June and September) or oriented along the Kerama Gap transect

457 and thus generate small SSH difference across the transect (July and August) (and 458 additionally have negligible deep flow).

$459 \quad 5.5$ Baroclinic Instability 
461 variations (James et al., 1999; Zhang et al., 2001; Nakamura et al., 2003; Hsin et al.,

462 2008). Charney (1947) developed the baroclinic instability theory for large scale quasi-

463 geostrophic atmospheric waves while Orlanski and Cox (1973) show us how baroclinic

464 instability develops when horizontal density gradients are present in the ocean. The

465 horizontal density/temperature gradient is essential since it provides the available

466 potential energy for the growth of the baroclinic instability. The horizontal temperature

467 gradient between Kuroshio water and the ambient ECS water shows a seasonal cycle:

468 weak in summer and strong during the winter-spring period (Nagata and Takeshita,

469 1985). Thus, the baroclinic instability is suppressed (enhanced) in summer (winter and

470 spring) as shown in Figure 6b (blue line). Previous observations (Nakamura et al., 2006,

471 2008) have indicated that the Kuroshio pathway in the northern Okinawa Trough is

472 destabilized during the winter-spring period and stabilized during the summer-autumn

473 period. Nakamura et al. $(2010,2012)$ additionally examined this seasonality of the

474 Kuroshio pathway destabilization and found that baroclinic instability triggered by

475 nonlinear Ekman divergence due to wind stress in autumn and winter plays an important

476 role in Kuroshio pathway variation. Thus the observed transport variability seems to be

477 explained by the theoretical considerations on the internal baroclinic instability.

478 6. Conclusions

479 A global HYCOM data-assimilative reanalysis was integrated for 20 years from 4801993 to 2012 and used to study the transport variability through Kerama Gap, the deepest

481 channel in the Ryukyu Islands Arc, and an important passage for water exchange between

482 the ECS and the Northwest Pacific. The reanalysis volume transport time series through 
483 Kerama Gap was confirmed to accurately reproduce the 2-year observational time series

484 from June 2009 to June 2011 reported by Na et al. (2014). The discrepancy of the bottom

485 velocity between the reanalysis and observations confirms that MODAS has marginal

486 skill in areas where profiles are limited. From the 20-year transport time series of volume

487 transport, we estimated the 20-year monthly mean seasonal cycle that has the maximum

488 in October $(3.0 \mathrm{~Sv})$ and the minimum in November $(0.5 \mathrm{~Sv})$.

489 The transport time series has large variability with a maximum of $17.3 \mathrm{~Sv}$ (May

490 1994) and minimum of $-14.5 \mathrm{~Sv}$ (December 1996). The 20-year mean of the volume

491 transport is $1.95 \mathrm{~Sv}$ into the ECS. Its standard deviation is $4.0 \mathrm{~Sv}$, equal to the observed

492 standard deviation of the ECS Kuroshio volume transport at the PN-line (Andres et al.,

493 2008b), which indicates a significant impact of Kerama Gap transport on the temporal

494 variability of the Kuroshio transport in the ECS.

495 The annual variation component, with periods between 345 and 400 days,

496 explains only $2.3 \%$ of the total transport variance, but it makes a significant contribution

497 to the seasonal cycle (Figure 6b, red line). This variation component tends to accompany

498 an increase of inflow through Kerama Gap in summer and a decrease in winter. It is

499 explained by the Ekman dynamics responding to seasonal changes of the local winds,

500 which contribute a positive transport anomaly in summer and a negative transport

501 anomaly in winter.

502 The mesoscale eddy component, with periods between 70 and 345 days, makes

503 the most significant contribution to the transport seasonal cycle except during summer

504 from June to September (Figure 6b, green line). Anticyclonic (cyclonic) eddies to the east

505 of Okinawa and/or cyclonic (anticyclonic) eddies to the southwest of Kerama Gap cause 
506 the volume transport into (out of) the ECS during January, February, May, and October

507 (March, April, November, and December) and they substantially affect the monthly

508 mean. In summer, contributions of impinging cyclonic and anticyclonic eddies are nearly

509 equal to each other, and the apparent influence of eddies diminishes.

510 The contribution of the Kuroshio meander components with periods shorter than

51170 days to the seasonal cycle is larger in winter than in summer. Baroclinic instability

512 was suggested to be one possible explanation.

513 The contribution of the inter-annual component to the seasonal cycle is just the

514 20-year mean transport (Figure 6a, black dashed line) due to its long time period and thus

515 is not discussed in this paper. However, we will present the inter-annual component of

516 the volume transport in a separate paper that examines its impact on extreme flow events,

517 i.e., when transport anomaly exceeds one standard deviation.

518 Acknowledgments:

519 The numerical output used for this paper can be found on the

520 http://www.hycom.org data server under the "HYCOM + NCODA Global 1/12

521 Reanalysis" link. This effort was funded by the "6.1 Kuroshio and Ryukyu Current

522 Dynamics" project sponsored by the Office of Naval Research under program element

523 0601135N. Z. Y. was supported by a Post-Doctoral Fellowship from the American

524 Society for Engineering Education, with funding provided by the Naval Research

525 Laboratory, Stennis Space Center, MS. Grants of computer time were provided by the

526 Department of Defense (DoD) High Performance Computing Modernization Program

527 and the simulations were performed on the IBM Power 6 (daVinci) and the IBM

528 iDataPlex (Kilrain) at the Navy DoD Supercomputing Resources Center, Stennis Space 
529 Center, MS. This is NRL contribution NRL/JA/7320-15-2704. It has been approved for

530 public release and distribution is unlimited.

531

532

533

534

535

536

537

538

539

540

541

542

543

544

545

546

547

548

549

550

551 


\section{References:}

553 Andres, M., J.-H. Park, M. Wimbush, X.-H. Zhu, K.-I. Chang, and H. Ichikawa, 2008a.

554 Study of the Kuroshio/Ryukyu Current system based on satellite-altimeter and in situ

555 measurements. J. Oceanogr., 64, 937-950.

556

557

558

559

560

561

562

563

564

565

566

567

568

569

570

571

572

573

574

575

576

577

578

579

580

581

582

583

584

585

586

587

588

589

590

591

592

593

594

Andres, M., M. Wimbush, J.-H. Park, K.-I. Chang, B.-H. Lim, D.R. Watts, H. Ichikawa, and W.J. Teague, 2008b. Observations of Kuroshio flow variations in the East China Sea. J. Geophys. Res., 113, C05013, doi:10.1029/2007JC004200.

Andres, M., and C. Cenedese, 2013. Laboratory experiments and observations of cyclonic and anticyclonic eddies impinging on an island. J. Geophys. Res. Oceans, 118, doi:10.1002/jgrc.20081.

Bleck, R., 2002. An oceanic general circulation model framed in hybrid isopycnicCartesian coordinates. Ocean Modeling, 4, 55-88.

Charney, J. G., 1947. The dynamics of long waves in a baroclinic westerly current. J. Meteor., 4, 135-162.

Chassignet, E.P., L.T. Smith, G.R. Halliwell, and R. Bleck, 2003. North Atlantic simulations with the Hybrid Coordinate Ocean Model (HYCOM): Impact of the vertical coordinate choice, reference pressure, and thermobaricity. J. Phys. Oceanogr., 33, 25042526.

Choi, B.H., K.O. Kim, and H.M. Eum, 2002. Digital bathymetric and topographic data for neighboring seas of Korea. J. Korean Soc. Coastal Ocean Eng., 14, 41-50.

Cummings, J. A., 2005. Operational multivariate ocean data assimilation. Q. J. R. Meteorol. Soc., 131, 3583-3604.

Cummings, J. A., and O. M. Smedstad, 2013. Variational data assimilation for the global ocean. Data Assimilation for Atmospheric, Oceanic, and Hydrologic Applications (Vol. II). S. K. Park and L. Xu, eds, Springer-Verlag, Berlin Heidelberg, http://dx.doi.org/10.1007/978-3-642-35088-7_13.

Dewar, W. K., and J. M. Bane, 1985. Subsurface energetics of the Gulf Stream near the Charleston Bump, J. Phys. Oceanogr., 15, 1771-1789.

Feng, M., H. Mitsudera, and Y. Yoshikawa, 2000. Structure and variability of the Kuroshio Current in Tokara Strait. J. Phys. Oceanogr., 30, 2257-2276.

Fox, D. N., Teague, W. J., Barron, C. N., Carnes, M. R., and Lee, C. M., 2002. The modular ocean data assimilation system. J. Atmos. Ocean. Technol., 19, 240-252.

595 
596

597

598

599

600

601

602

603

604

605

606

607

608

609

610

611

612

613

614

615

616

617

618

619

620

621

622

623

624

625

626

627

628

629

630

631

632

633

634

635

636

637

638

639

640

641

642
Gordon, A. L., P. Flament, C. Villanoy, and L. Centurioni, 2014. The nascent Kuroshio of Lamon Bay, J. Geophys. Res. Oceans, 119, 4251-4263, doi:10.1002/2014JC009882.

Guo, X., Y. Miyazawa, and T. Yamagata, 2006. The Kuroshio onshore intrusion along the shelf break of the East China Sea: The origin of the Tsushima warm current. J. Phys. Oceanogr., 36, 2205-2231.

Helber, R. W., T. L. Townsend, C. N. Barron, J. M. Dastugue, and M. R. Carnes, 2013. Validation test report for the Improved Synthetic Ocean Profile (ISOP) system: Part I. synthetic profile methods and algorithm. NRL memorandum report NRL/MR/7320-139364, http://www7320.nrlssc.navy.mil/pubs/2013/helber1-2013.pdf.

Hsin, Y.-C., C.-R. Wu, and P.-T. Shaw, 2008. Spatial and temporal variations of the Kuroshio east of Taiwan, 1982-2005: A numerical study. J. Geophys. Res., 113, C04002, doi:10.1029/2007JC004485.

Hsin, Y.-C., T. Qu, and C.-R. Wu, 2010. Intra-seasonal variation of the Kuroshio southeast of Taiwan and its possible forcing mechanism. Ocean Dyn., 60, 1293-1306.

Ichikawa, H., H. Nakamura, A. Nishina, and M. Higashi, 2004. Variability of north-eastward current southeast of northern Ryukyu Islands. J. Oceanogr., 60, 351-363.

Ichikawa, K., 2001. Variation of the Kuroshio in the Tokara Strait induced by meso-scale eddies, J. Oceanogr., 57, 55-68.

James, C., M. Wimbush, and H. Ichikawa, 1999. Kuroshio meanders in the East China Sea. J. Phys. Oceanogr., 29, 259-272.

Jin, B., G. Wang, Y. Liu, and R. Zhang, 2010. Interaction between the East China Sea Kuroshio and the Ryukyu Current as revealed by the self-organizing map. J. Geophys. Res., 115, C12047, doi:10.1029/2010JC006437.

Johns, W.E., T.N. Lee, D. Zhang, R. Zantopp, C.-T. Liu, and Y. Yang, 2001. The Kuroshio east of Taiwan: Moored transport observations from the WOCE PCM-1 array. J. Phys. Oceanogr., 31, 1031-1053.

Kundu, P. K., and I. M. Cohen, 2002. Fluid Mechanics, Academic Press, San Diego.

Lee, I.-H., D. S. Ko, Y.-H. Wang, L. Centurioni, D.-P. Wang, 2013. The mesoscale eddies and Kuroshio transport in the western North Pacific east of Taiwan from 8-year (2003-2010) model reanalysis. Ocean Dyn., 63, 1027-1040.

Metzger, E. J., O. M. Smedstad, P. G. Thoppil, H. E. Hurlburt, J. A. Cummings, A. J. Wallcraft, L. Zamudio, D. S. Franklin, P. G. Posey, M. W. Phelps, P. J. Hogan, F. L. Bub, and C. J. Dehaan, 2014. US Navy Operational Global Ocean and Arctic ice prediction systems. Oceanogr., 27, 32-43. 
643 Morinaga, K., N. Nakagawa, K. Osamu, and B. Guo, 1998. Flow pattern of the Kuroshio 644 west of the main Okinawa Island. In Proceedings of Japan-China Joint Symposium on 645 Cooperative Study of Subtropical Circulation System, pp. 203-210, Seikai Natl. Fish. 646 Res. Inst., Nagasaki, Japan.

647

Na, H., M. Wimbush, J.-H. Park, H. Nakamura, and A. Nishina, 2014. Observations of 649 flow variability through the Kerama Gap between the East China Sea and the 650 northwestern Pacific, J. Geophys. Res., Oceans, 119, 689-703, 651

652

687 Orlanski, I., and M. Cox, 1973. Baroclinic instability in ocean currents. Geophys. Fluid 688

Nagata, U., and K. Takeshita, 1985. Variation of the sea surface temperature distribution across the Kuroshio in the Tokara Strait, J. Oceanogr. Soc. Jpn., 41, 244-258.

Nakamura, H., H. Ichikawa, A. Nishina, and H.-J. Lie, 2003. Kuroshio path meander between the continental slope and the Tokara Strait in the East China Sea, J. Geophys. Res., 108(C11), 3360, doi:10.1029/2002JC001450.

Nakamura, H., A. Nishina, and H. Ichikawa, 2006. Time-frequency variability of Kuroshio meanders in Tokara Strait, Geophys. Res. Lett., 33, L21605, doi:10.1029/2006GL027516.

Nakamura, H., A. Nishina, H. Ichikawa, M. Nonaka, and H, Sasaki, 2008. Deep countercurrent beneath the Kuroshio in the Okinawa trough, J. Geophys. Res., 113, C06030, doi:10.1029/2007JC004574.

Nakamura, H., M. Nonaka, and H. Sasaki, 2010. Seasonality of the Kuroshio path destabilization phenomenon in the Okinawa Trough: a numerical study of its mechanism, J. Phys. Oceanogr., 40, 530-550, doi:10.1175/2009JPO4156.1.

Nakamura, H., A. Nishina, K. Tabata, M. Higashi, A. Habano, and T. Yamashiro, 2012. Surface velocity time series derived from satellite altimetry data in a section across the Kuroshio southwest of Kyushu, J. Oceanogra., 68, 321-336, doi:10.1007/s10872-012$0101-4$.

Nakamura, H., A. Nishina, Z. Liu, F. Tanaka, M. Wimbush, and J.-H. Park, 2013. Intermediate and deep water formation in the Okinawa Trough, J. Geophys. Res., 118, 6881-6893.

Nitani, H., 1972. Beginning of the Kuroshio, Kuroshio, pp. 129-163, Univ. of Wash. Press, Seattle.

Oka, E., and M. Kawabe, 1998. Characteristics of variations of water properties and density structure around the Kuroshio in the East China Sea. J. Oceanogr., 54, 605-617. Dyn., 4, 297-332. 
690 Qiu, B., 2001. Kuroshio and Oyashio Currents. Encyclopedia of Ocean Sciences, 3,

Qiu, B., T. Toda, and N. Imasato, 1990. On Kuroshio front fluctuations in the East China

695

Qu, T., and R. Lukas, 2003. The bifurcation of the North Equatorial Current in the Pacific. J. Phys. Oceanogr., 33, 5-18.

Roemmich, D., and T. McCallister, 1989. Large scale circulation of the North Pacific Ocean. Prog. Oceanog., 22, 171-204.

Saha, S. and others, 2010. The NCEP Climate Forecast System Reanalysis, Bull. Amer. Meteor. Soc., 91, 1015-1057. doi: http://dx.doi.org/10.1175/2010BAMS3001.1.

Soeyanto, E., X. Guo, J. Ono, and Y. Miyazawa, 2014. Interannual variations of Kuroshio transport in the East China Sea and its relation to the Pacific Decadal Oscillation and mesoscale eddies, J. Geophys. Res. Oceans, 119, 35965-3616, doi:10.1002/2013JC009529.

Sugimoto, T., S. Kimura, and K. Miyaji, 1988. Meander of the Kuroshio front and current variability in the East China Sea, J. Oceanogr. Soc. Japan, 44, 125-135.

Stammer, D., 1997. Steric and wind-induced changes in TOPEX/POSEDON large-scale sea surface topography observations, J. Geophys. Res., 102, 20,987-21,009.

Thoppil, P., E. J. Metzger, H. E. Hurlburt, O. M. Smedstad, and H. Ichikawa, 2015. The current system east of the Ryukyu Islands as revealed by a global ocean reanalysis.

Submitted to Prog. Oceanog.

You, S.-H., and J.-H. Yoon, 2004. Modeling of the Ryukyu current along the Pacific side of the Ryukyu Islands. Pacific Oceanogr., 2, 44-51.

Yuan, Y., K. Takano, Z. Pan, J. Su, K. Kawatate, S. Imawaki, H. Yu, H. Chen, H. Ichikawa, and S. Umatani, 1994. The Kuroshio in the East China Sea and the currents east of the Ryukyu Islands during autumn 1991. La. Mer., 32, 235-244.

Yuan, Y., J. Su, Z. Pan, H. Chen, H. Ichikawa, S. Imawaki, K. Kawatate, K. Takano, and S.-I. Umatani, 1995. The western boundary current east of the Ryukyu Islands. La. Mer., $33,1-11$.

Zhang, D., W. E. Johns, T. N. Lee, C.-T. Liu, and R. Zantopp, 2001. The Kuroshio east of Taiwan: Modes of variability and relationship to interior mesoscale eddies. J. Phys. Oceanogr., 31, 1054-1074. 


\section{Figure Captions:}

736 Figure 1. HYCOM bathymetry (meters) for the East China Sea. Gray represents model

737 land points. Okinawa (1), Miyakojima (2), Ishigaki (3), the East Taiwan Channel (ETC),

738 Taiwan (4), Kyushu (5), and Tokara Strait are labeled. The black line represents the PN-

739 line. The land -ocean boundary in HYCOM is defined by the $10 \mathrm{~cm}$ isobath but all depths

740 less than $5 \mathrm{~m}$ are set to $5 \mathrm{~m}$. A zoom centered on Kerama Gap is inset in the lower right

741 corner. The gray solid line represents the HYCOM transect used to determine transport

742 through Kerama Gap. The four red dots represent the locations of CPIES moorings ES1

743 to ES4 and three white dots represent the locations of current meters CM1 to CM3 (SW-

744 NE, Na et al., 2014). The green dot represents the location of CPIES mooring ES5.

746 Figure 2. Mean current vectors at upper ( $\mathrm{a}$ and b), middle ( $\mathrm{c}$ and d), and near sill depth (e

747 and f) layers in Kerama Gap for year-1 (left) and year-2 (right) at CM1 (southwest) to

748 CM3 (northeast). Only CM2 has measurements near the sill depth. Observations from Na

749 et al. (2014) are shown in black and the HYCOM reanalysis in red. Gray represents

750 model land points. The reference vector is shown in the lower right corner of each panel.

751

752 Figure 3. Vertical structure of velocity $(\mathrm{m} / \mathrm{s})$ normal to the Kerama Gap transect for (a)

753 the global HYCOM reanalysis, (b) Pacific assimilative HYCOM hindcast, and (c) linear

754 interpolation of the observations ( $\mathrm{Na}$ et al., 2014). The time frame spans the

755 observational period, June 2009 - June 2011.

756 
757 Figure 4. Comparison of daily mean transport time series from the HYCOM reanalysis 758 (red) with observations (black) from Na et al. (2014) through Kerama Gap. (a) The 20-

759 year time series from 1993 to 2012, and (b) the 2-year observational period from June

7602009 to June 2011. A 72-hour low-pass filter has been applied to both time series.

761 Positive transport is flow into the ECS and negative transport is flow into the Pacific

762 through Kerama Gap. Mean values are listed in their respective colors.

763

764 Figure 5. Variance preserving power spectra $\left(\mathrm{S}_{\mathrm{v}}{ }^{2}\right)$ of the 20-year global HYCOM

765 reanalysis transport time series through Kerama Gap. Vertical lines show the boundaries

766 of the temporal bands investigated, i.e. 70,345 , and 400 days.

767

768 Figure 6. (a) Seasonal cycle of transport through Kerama Gap and (b) the contribution of

769 different signals to the transport seasonal cycle (b) from the $1 / 12.5^{\circ}$ global HYCOM

770 reanalysis. The shaded area in (a) represents the seasonal cycle uncertainty and the

771 dashed line shows the 20-year mean transport.

772

773 Figure 7. The transport inter-annual variation component (black dashed line, 20-year

774 mean removed), annual variation component (red), mesoscale eddy component (green),

775 and Kuroshio meander component (blue) from 1993 to 2012 through Kerama Gap from

776 the $1 / 12.5^{\circ}$ global HYCOM reanalysis. 
778 Figure 8. Comparison of yearly transport standard deviation between transport through

779 Kerama Gap (solid line) and the PN line (dashed line) for 1993 - 2012 from the $1 / 12.5^{\circ}$

780 global HYCOM reanalysis.

781

782 Figure 9. SSH difference (year-2 - year-1, $\mathrm{cm}$ ) and layer-1 velocity difference (year-2 783 year-1, cm/s) between year-2 (June 2010 - June 2011) and year-1 (June 2009 - June

784 2010) from the global HYCOM reanalysis.

785

786 Figure 10. Mean CFSR wind stress vectors averaged over the period 1993 to 2012 in the

787 ECS during summer (a, June - August) and winter (b, December - February). Gray 788 represents model land points. The reference vector is shown in the upper left corner of 789 each panel. (c) Scatter plot of monthly along Kerama Gap wind stress anomaly and 790 monthly transport of the annual variation component through Kerama Gap.

791

792 Figure 11. Monthly mean (1993-2012) SSHA (cm, relative to annual mean SSH with 793 annual steric effect removed) pattern from January to December. Contours with SSHA =

$7942 \mathrm{~cm}$ (solid white line) are used to identify the anomalous anticyclones and contours with

795 SSHA $=-2 \mathrm{~cm}$ (dashed white lines) are used to identify the anomalous cyclones. 796

797 Figure 12 . Monthly velocity anomaly $(\mathrm{cm} / \mathrm{s}$, relative to annual mean velocity) at $150 \mathrm{~m}$ 798 overlaid on top of the SSHA in May (a) and November (b). The reference vector is 799 shown in the upper left corner of each panel. 
801 Table 1. Correlation coefficient between observed and modeled along Kerama Gap 802 velocity at different CMs and layers during June 2009 - June 2011 for the two period 803 bands: mesoscale eddy (eddy, 70-345 days) and Kuroshio meander (meander, < 70 days)

804 band. The correlation coefficients are all significant to the $95 \%$ confidence level.

\begin{tabular}{|c|c|c|c|c|c|c|}
\hline \multirow{2}{*}{} & \multicolumn{2}{|c|}{ CM1 } & \multicolumn{2}{c|}{ CM2 } & \multicolumn{2}{c|}{ CM3 } \\
\cline { 2 - 7 } & Eddy & Meander & Eddy & Meander & Eddy & Meander \\
\hline Upper & 0.66 & 0.22 & 0.62 & 0.29 & 0.67 & 0.26 \\
\hline Middle & 0.39 & 0 & 0.68 & 0.23 & 0 & 0.37 \\
\hline Deep & N/A & N/A & 0 & 0.19 & N/A & N/A \\
\hline
\end{tabular}

805

806

807

808 Table 2. Statistics of transport (Sv) through the Kerama Gap. Year-1 is defined as the

809 period from June 2009 to June 2010 and Year-2 is defined as June 2010 to June 2011.

\begin{tabular}{|c|c|c|c|c|c|c|}
\hline & 2-year mean & Year-1 mean & Year-2 mean & 2 year std & Year-1 std & Year-2 std \\
\hline Observation & 2.0 & 1.2 & 2.8 & 3.2 & 2.6 & 3.6 \\
\hline HYCOM & 2.1 & 1.6 & 2.6 & 4.2 & 3.4 & 4.8 \\
\hline
\end{tabular}

810

811

812

813

814

815

816

817

818

819

820

821 


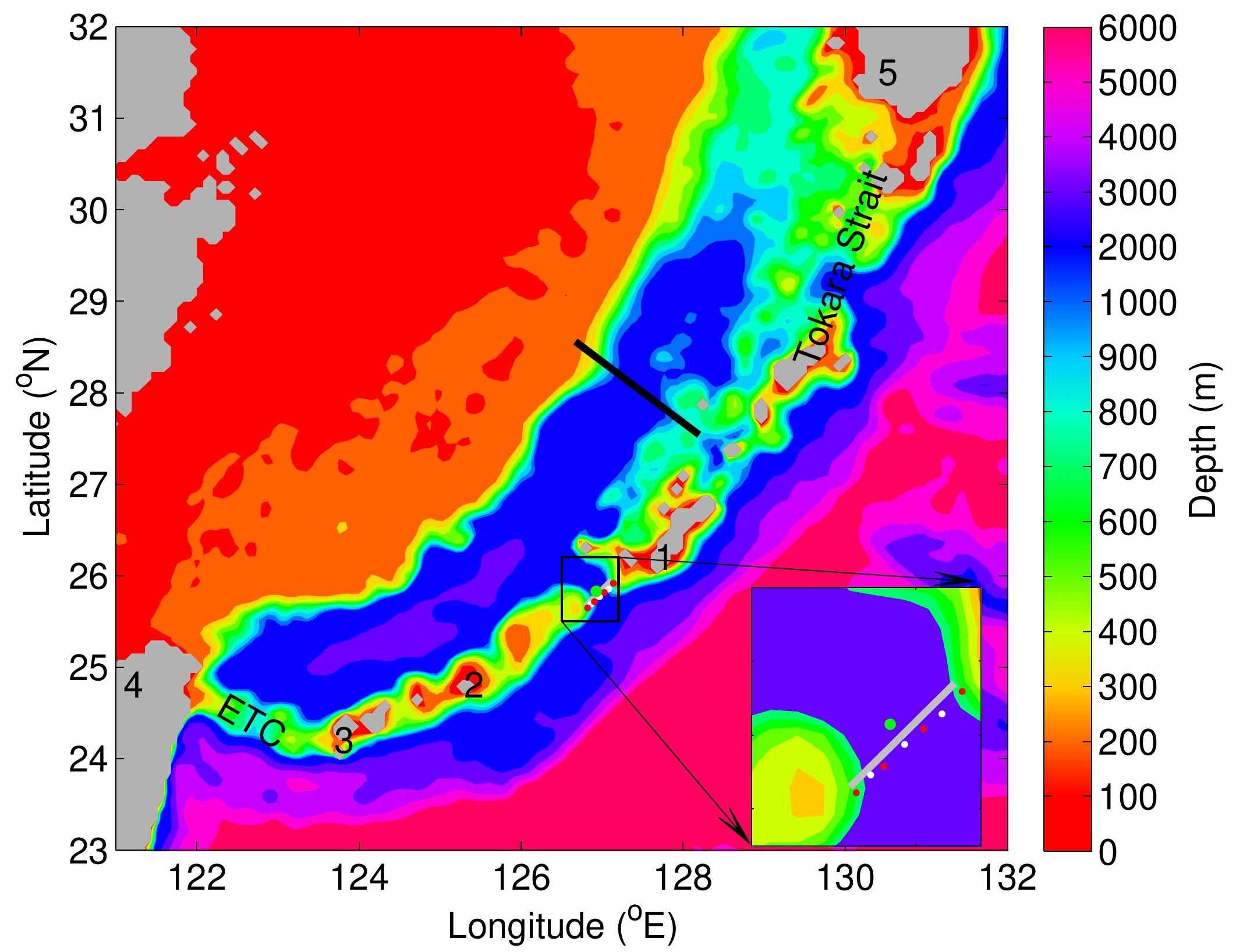


Year1 (June 2009-June 2010)Year2 (June 2010-June 2011)
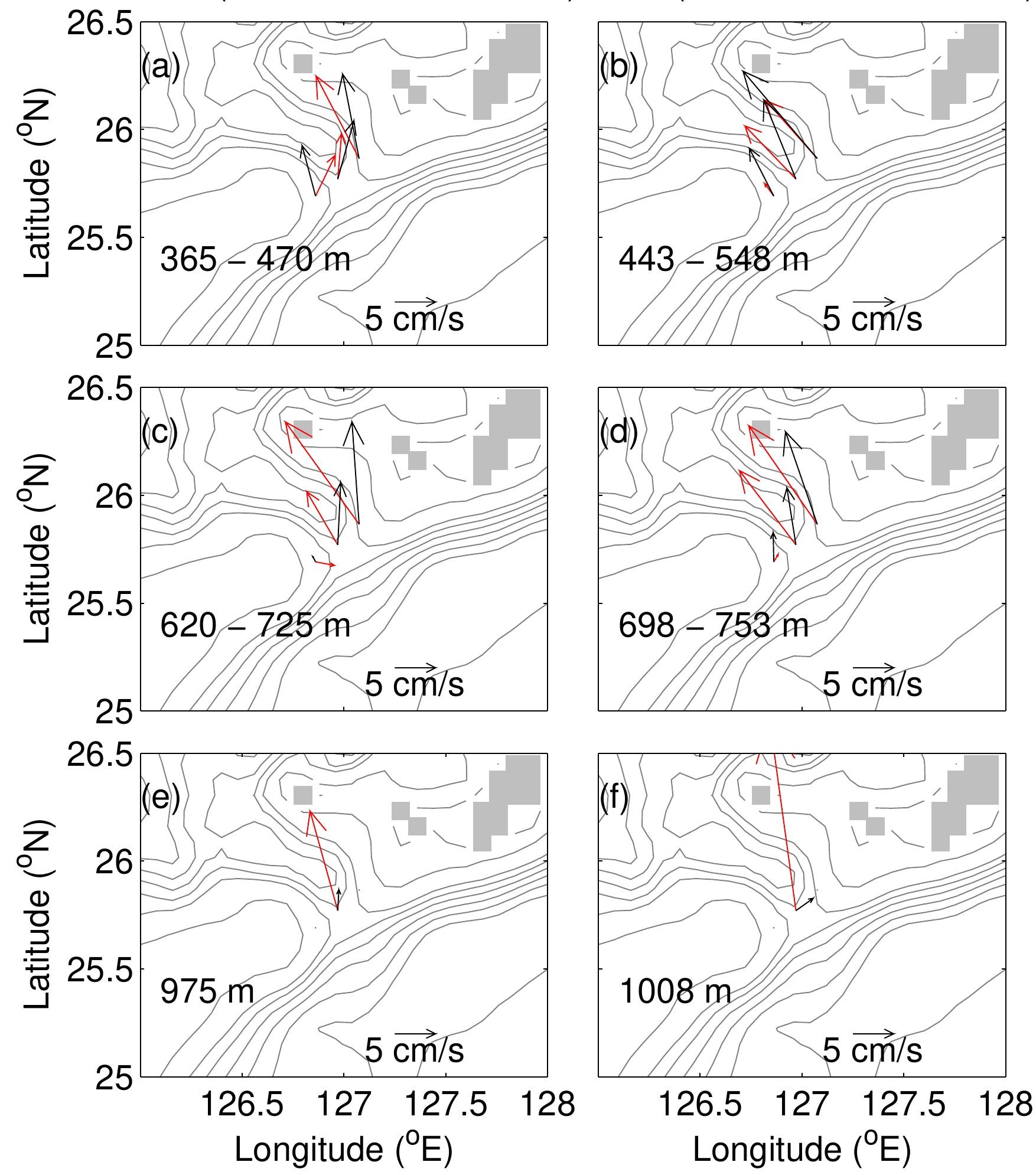
Figure
Figure3

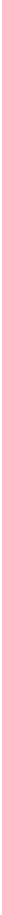



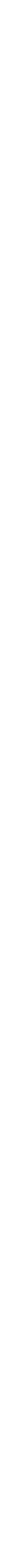


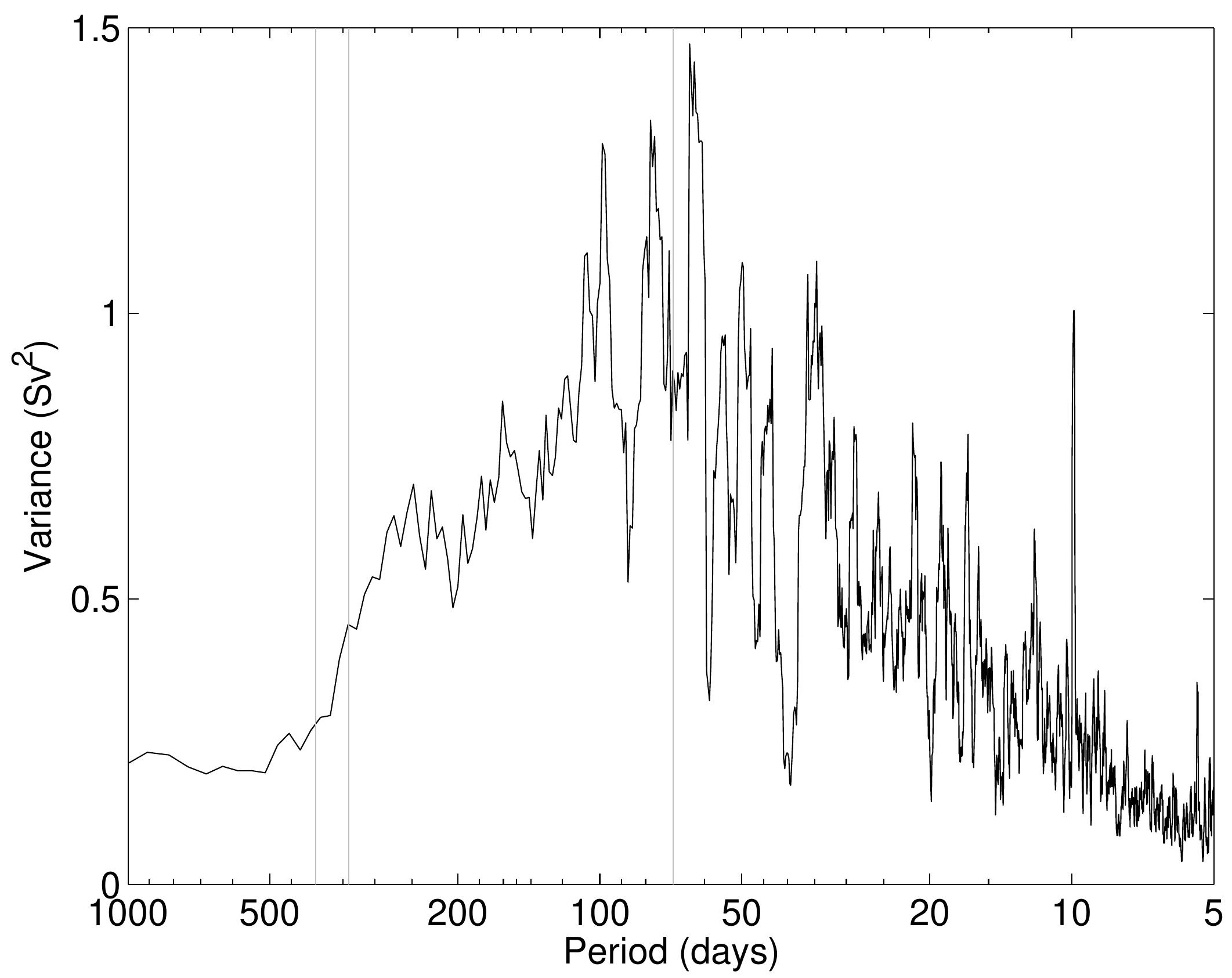




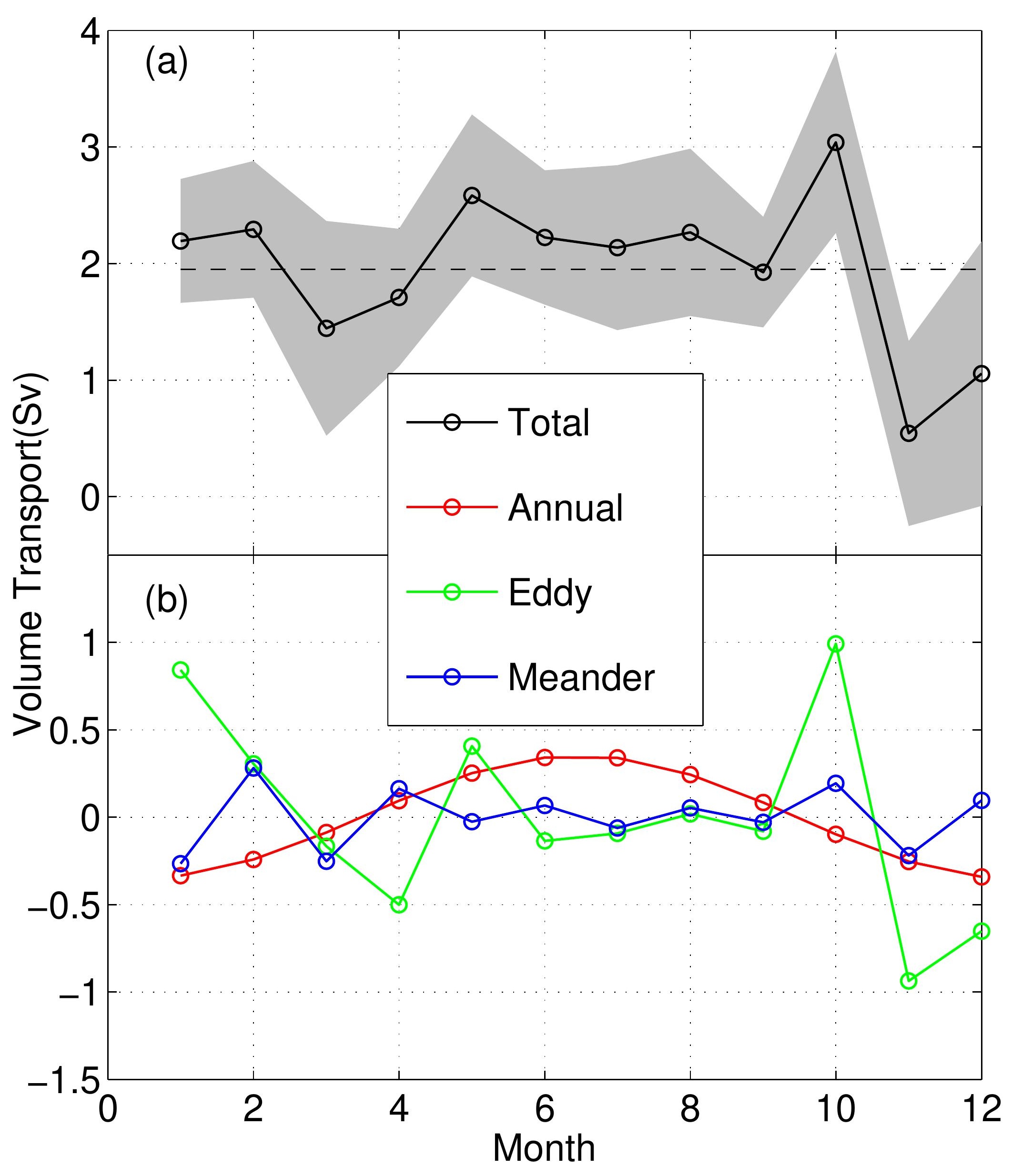

Month 


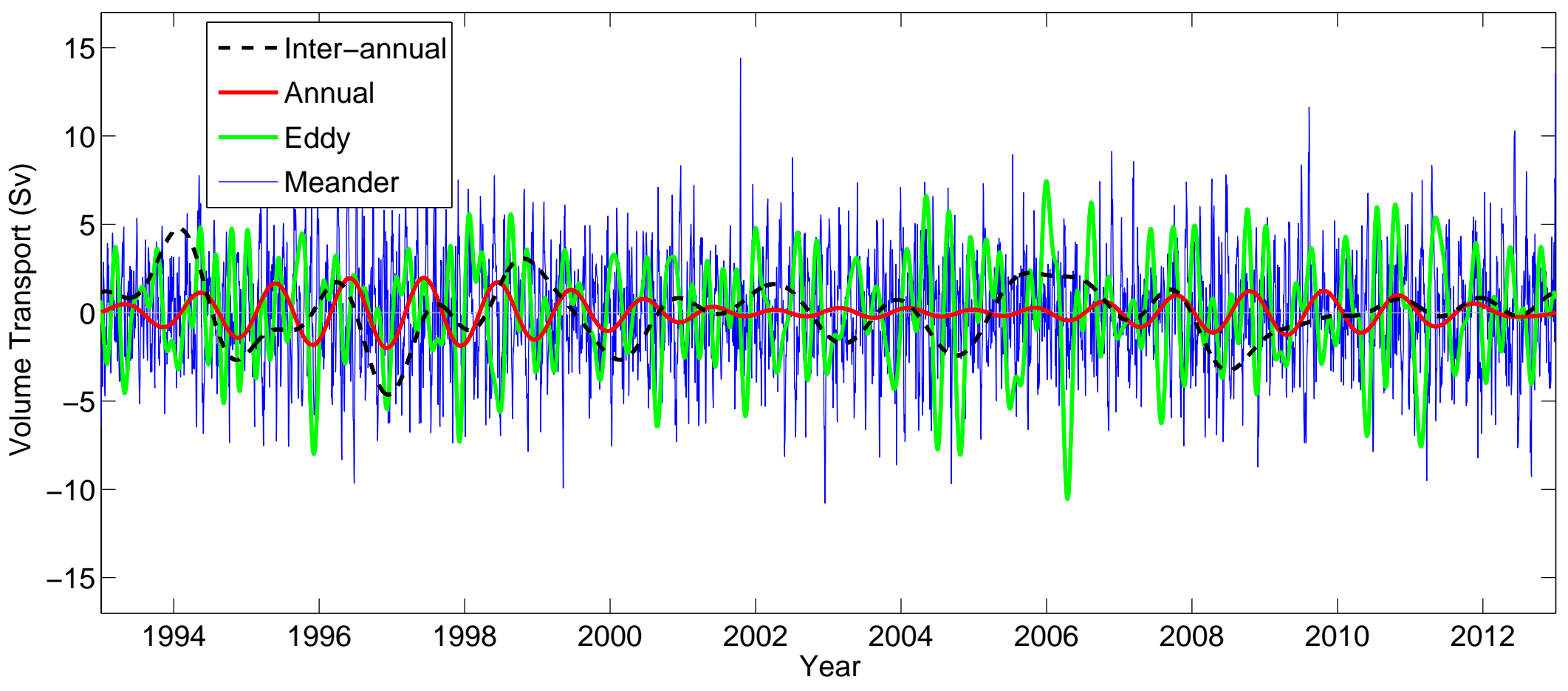




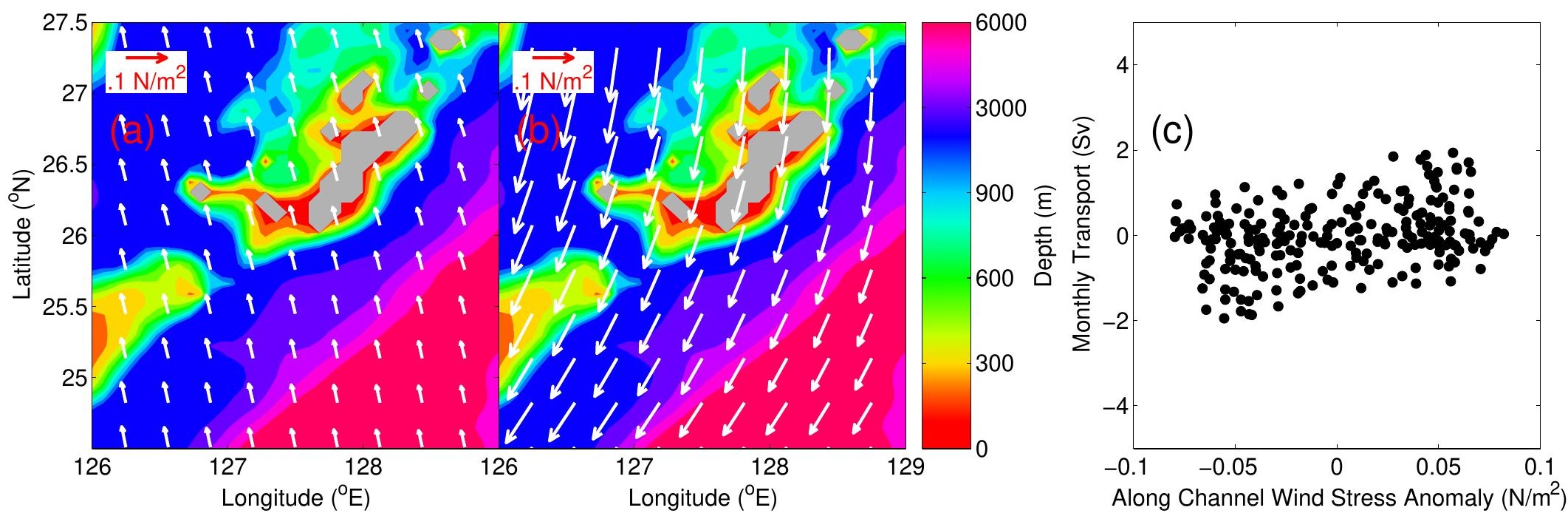


$\sum_{2}^{27}$

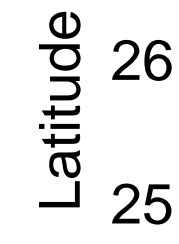

28

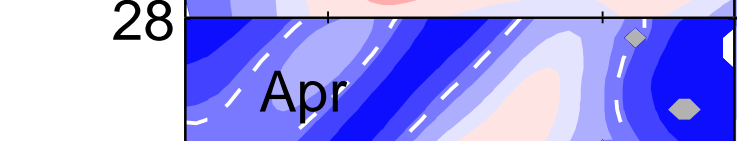

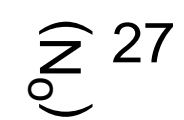

${ }_{25}^{\stackrel{0}{0}} 26$

25
28

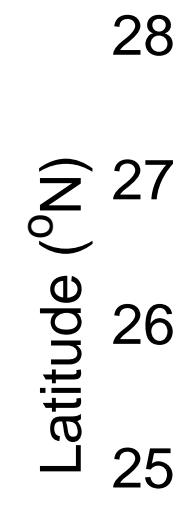

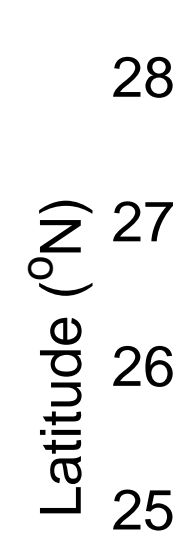

$125 \quad 126 \quad 127 \quad 128$ Longitude $\left({ }^{\circ} \mathrm{E}\right)$

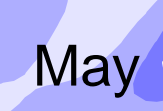

Feb (1)
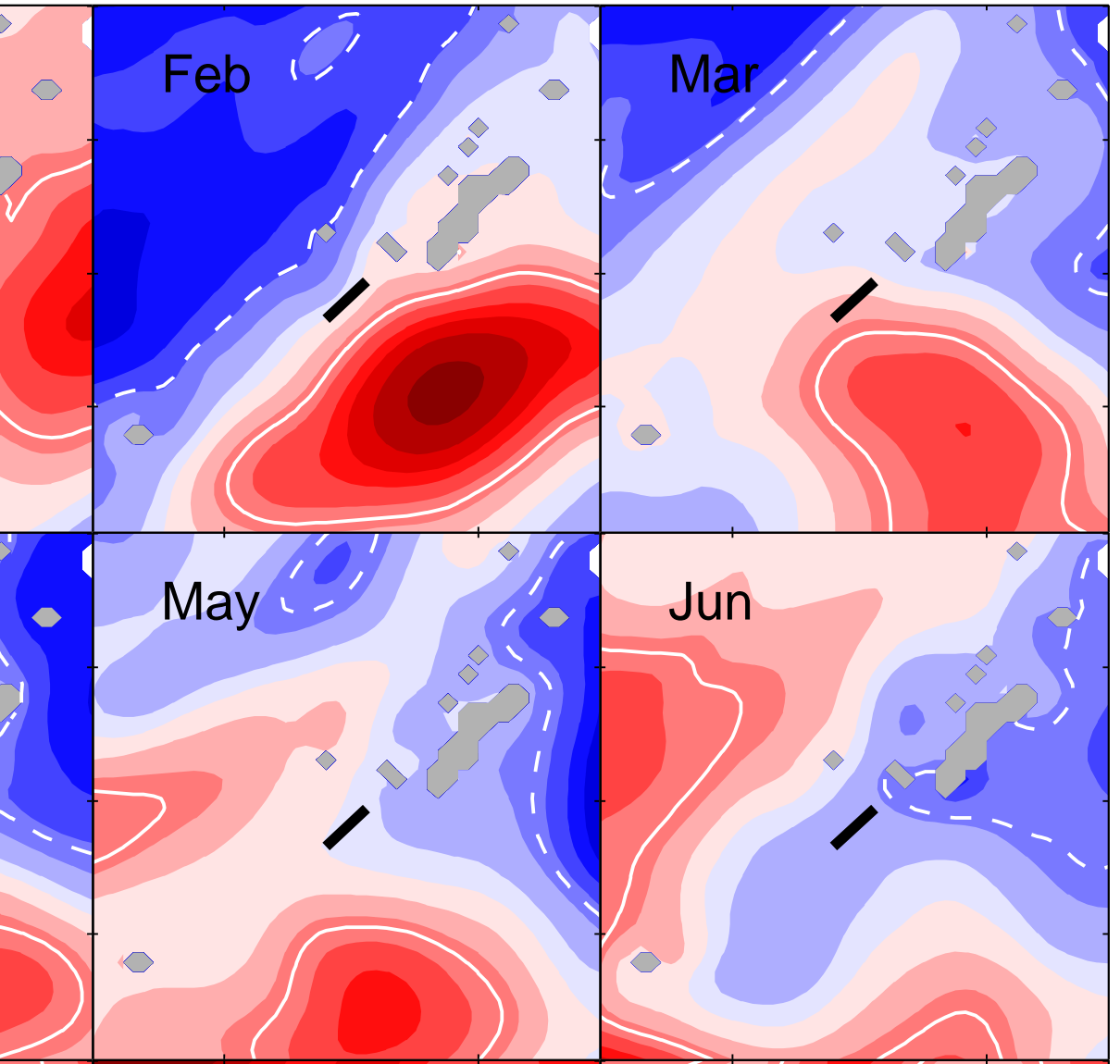

Aug

Sep

Nov
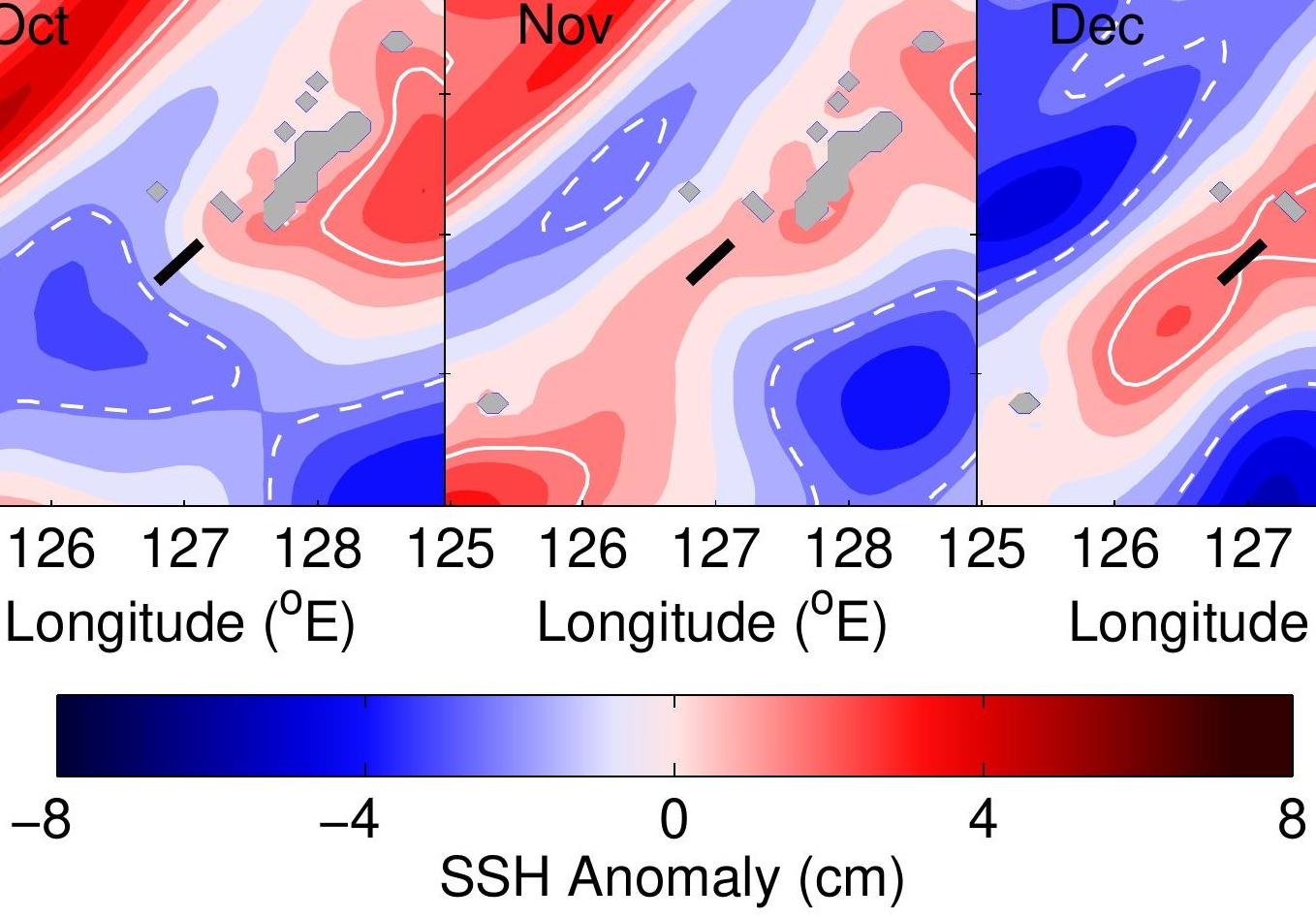


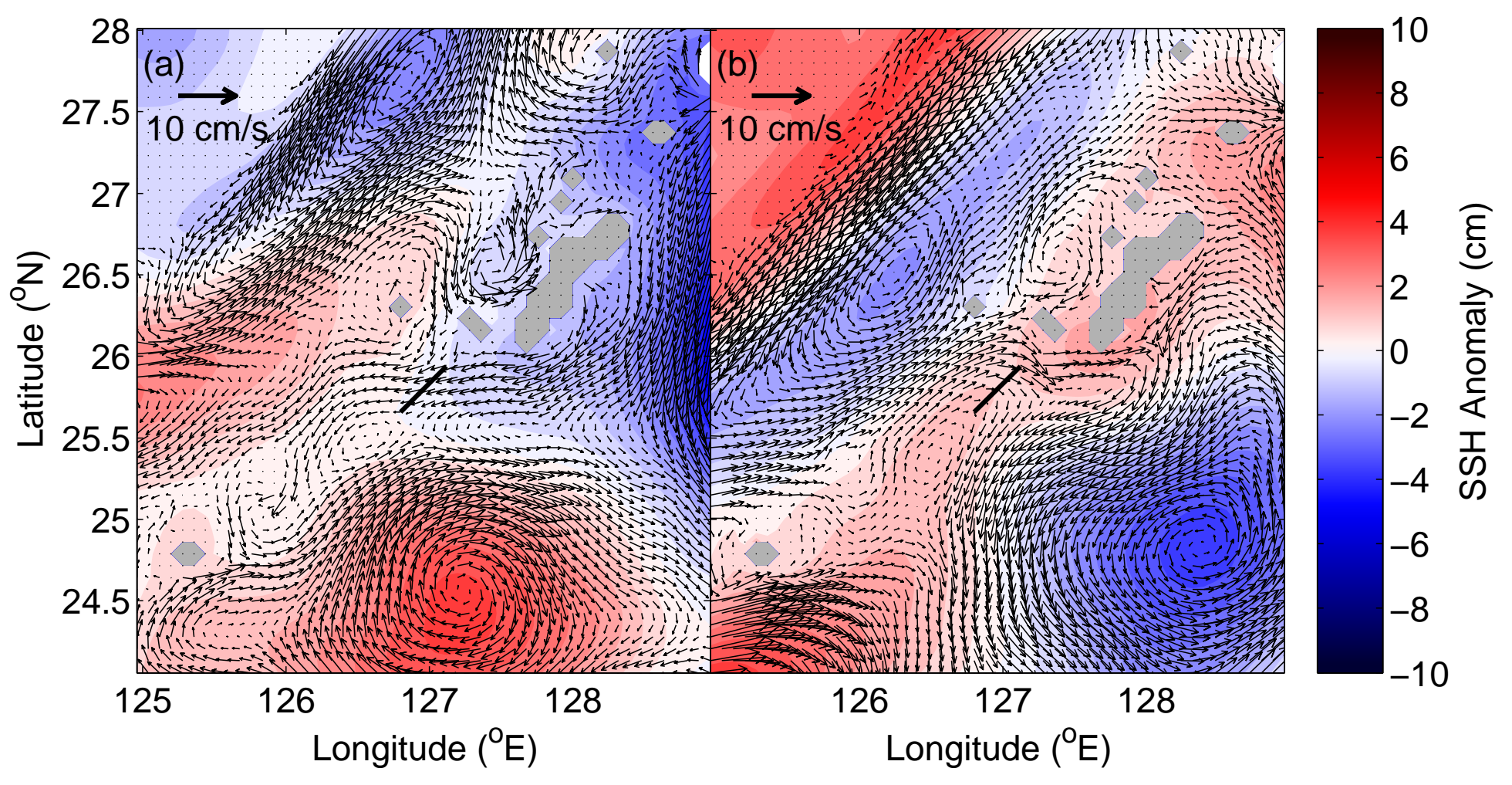

